\title{
Sistem Pendukung Keputusan Penentuan Status Gizi Buruk Pada Balita Menggunakan Metode Fuzzy Mamdani
}

\author{
Dian Permata Sari \\ Dosen STMIK Jayanusa \\ dianpermatasari0218@yahoo.com
}

\begin{abstract}
Malnutrition is a condition when a person is declared lack of nutrients, or in other meanhis/her nutrients or nutritional status are below of average standards. As consequent will born unproductive human resources so will impact on all aspects of life. Based on these problems we need a method to determine the nutritional status of babies in order to handle of malnutrition. With the decision support system, it can be easier to monitor the growth and development of babies health and to facilitate decision-making in malnutrition treatment tounder five years old childrens. Fuzzy logic is a problem-solving control system method, which is suitable to implement on a systems and supported by Mamdani method. The data used as input were age, body weight, and body length and conducted a manual search using Mamdani and do Matlab test. If the babies has low age, light of weight, and average body length so the nutritional status is very low. Although the results of the manual calculation and Matlab result is not the same, but still in the same range. As an example,the results obtained using manual search using Mamdani method is 27.7 andthe result of Matlab testis 32.9 both of them have 5.2 difference, but still in the same range with very poor nutritional decisions.
\end{abstract}

Keywords: Decision Support System, Malnutrition,Babies, FuzzyMamdani

\section{PENDAHULUAN}

Sistem Fuzzy tergantung pada pengetahuan atau prinsip-prinsip. Mesin inferensi Fuzzy menggabungkan prinsipprinsip ini ke dalam pendaftaran Fuzzy set dalam ruang input ke dalam output Fuzzy set ruang. Logika Fuzzy digunakan untuk merancang sistem pakar yang mensimulasikan dunia nyata( Nezhad et al,2013).

Nalar manusia tidak jelas, atau perkiraan, dan begitu juga dunia nyata. Logika fuzzy adalah logika yang mendasari mode penalaran yang perkiraan dari pada tepat, dengan demikian itu adalah lebih dekat dengan akal manusia dan dunia nyata dari pada logika yang formal. Oleh karena itu, logika fuzzy telah berhasil diterapkan ke banyak aplikasi untuk kontrol otomatis (terutama untuk non-linear sistem tidak jelas). Konsep himpunan Fuzzy adalah kelas dengan batas-batas unsharp. Ini menyediakan dasar untuk pendekatan kualitatif dengan analisis sistem yang kompleks yang linguistik dari pada variabel numerik bekerja untuk menggambarkan perilaku sistem dan kinerja(Elamvazuthi, Vasant andWebb, 2009). 


\section{LANDASAN TEORI}

\section{Logika Fuzzy}

Logika Fuzzyadalah sistem yang dapat melakukan penalaran dengan prinsip serupa manusia melakukan penalaran dengan nalurinya. Menurut Agus Naba(2009) logika Fuzzy adalah sebuah metodologi "berhitung" dengan variabel kata-kata, sebagai pengganti berhitung dengan bilangan.

\section{Operator Logika Fuzzy}

1. Operator $A N D$

Operator ini berhubungan dengan operasi interseksi pada himpunan.

$$
\mu A \cap B=\min (\mu A[x], \mu B[y]
$$

2. Operator $O R$

Operator ini berhubungan dengan operasi union pada himpunan.

$\mu A \cap B=\max (\mu A[x], \mu B[y]$

3. Operator NOT

Operator ini berhubungan dengan operasi komplemen himpunan.

$\mu A^{\prime}=1-\mu A[x]$

\section{Sistem Inferensi Fuzzy}

1. Penalaran Monoton

Metode ini adalah metode penalaran yang paling sederhana untuk teknik implikasi fuzzy.

2. Metode Tsukamoto

Metode ini merupakan perluasana dari penalaran monoton.

3. Metode Mamdani

Sering dikenal dengan nama Metode MaxMin.

4. Metode Sugeno

\section{Fungsi Keanggotaan}

Fungsi Keanggotaan (membership function) adalah suatu kurva yang menunjukan pemetaan titik-titik input ke dalam nilai keanggotaannya (sering juga disebut dengan derajat keanggotaan) yang memiliki interval antara 0 sampai 1.

Representasi Linear Naik

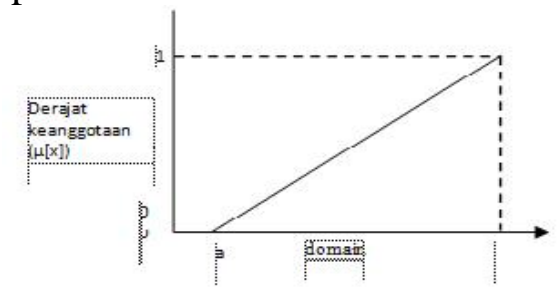

\section{Gambar 1. Representasi Linier Naik}

Fungsi keanggotaan:

$$
\begin{gathered}
0 ; x \leq a \\
\mu x=\frac{x-a}{b-a} ; a \leq x \leq b \\
1 ; x \geq b
\end{gathered}
$$

Representasi Linear Turun

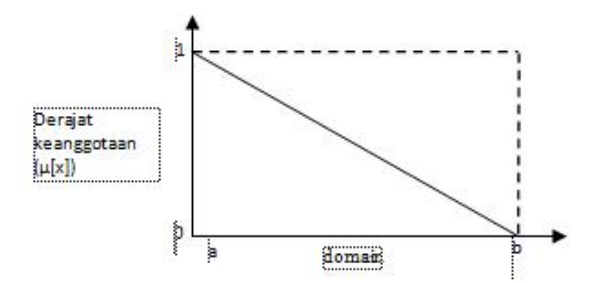

\section{Gambar 2. Representasi Linier Turun}

Fungsi keanggotaan:

$$
\mu x=\begin{array}{cc}
x-a / b-a & ; a \leq x \leq b \\
0 & x \geq b
\end{array}
$$




\section{Jurnal Edik Informatika \\ E-ISSN : 2541-3716}

Penelitian Bidang Komputer Sains dan Pendidikan Informatika

V1.i1(131-137)

Representasi Kurva Segitiga

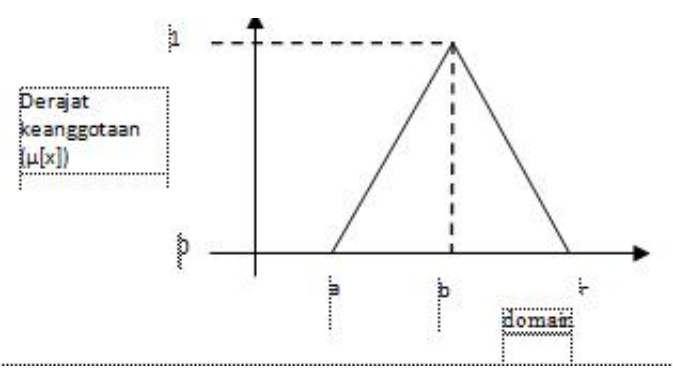

Gambar 3. Representasi Kurva Segitiga

Fungsi keanggotaan:

$$
\begin{aligned}
& 0 \text {; } x \leq \text { atau } x \geq c \\
& \mu x=\frac{x-a}{b-a} ; a \leq x \leq b \\
& \frac{b-x}{c-b} ; \quad b \leq x \leq c
\end{aligned}
$$

Representasi Kurva Trapesium

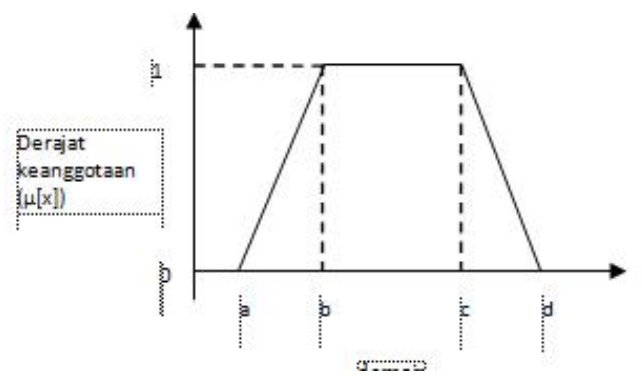

Gambar 4. Representasi Kurva Trapesium

$$
\mu \begin{gathered}
0 ; x \leq \text { aataux } \geq d \\
\frac{x-a}{\overline{b-a}} ; a \leq x \leq b \\
1 ; b \leq x \leq c
\end{gathered}
$$

$$
\frac{d-x}{d-c} ; x \geq d
$$

\section{Metode Mamdani}

Metode ini diperkenalkan oleh Ebrahim Mamdani pada tahun1975. Untuk mendapatkan output diperlukan 4 :

1. Pembentukan himpunan Fuzzy

2. Aplikasi fungsi implikasi

3. Komposisi aturan

4. Penegasan(defuzzy)

\section{Metode Penelitian}

1. Mengidentifikasi Masalah

2. Menganalisa masalah

3. Menentukan tujuan

4. Mencari dan mempelajari literatur

5. Mengumpulkan data dan informasi

6. Menganalisa data-data yang ada

7. Mengolah data dengan metode Mamdani

8. Mengimplementasikan dengan Matlab 6.1

9. Menguji hasil penelitian

10.Menarik kesimpulan

\section{Tahap Penelitian}

Pada penelitian ini penulis mentetapkan tiga variabel input (umur,berat badan dan panjang badan) dan satu variabel output yang terdiri dari beberapa himpunan; gizi sangat kurang, gizi kurang dan gizi cukup.

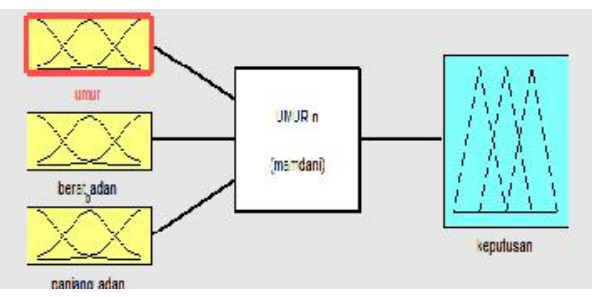

Gambar 5. Variabel penelitian 
Ada 4 tahap yang harus dilalui untuk memperoleh output dengan metode mamdani:

1. Pembentukan himpunan fuzzy

a. Variabel umur

Adapun gambar himpunan fuzzy variabel umur adalah:

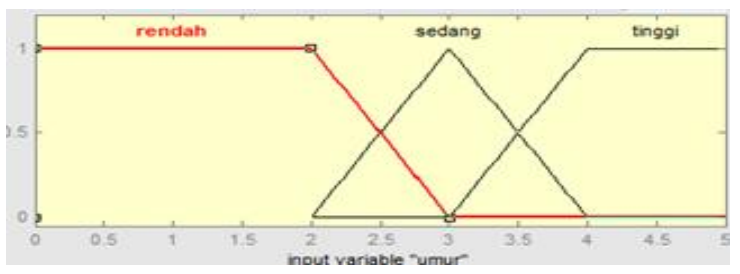

Gambar 6. Himpunan Fuzzy Umur

Untuk memperjelas grafik di atas ada pada keterangan tabel di bawah ini:

Tabel 1. Humpunan Fuzzy Umur

\begin{tabular}{|c|c|c|c|c}
\hline $\begin{array}{c}\text { Semesta } \\
\text { Pembicaraan }\end{array}$ & Himpunan & $\begin{array}{c}\text { Model } \\
\text { VIF }\end{array}$ & Domain & Parameter \\
\hline \multirow{3}{*}{$0-5$} & Rerdah & Trapmf & $0-3$ & {$[0023]$} \\
\cline { 2 - 5 } & Sećang & Trimf & $2-4$ & {$[234]$} \\
\cline { 2 - 5 } & Tirggi & Trapmf & $3-5$ & {$[3455]$} \\
\hline
\end{tabular}

b. Variabel Berat Badan

Adapun gambar himpunan fuzzy variabel berat badan adalah:

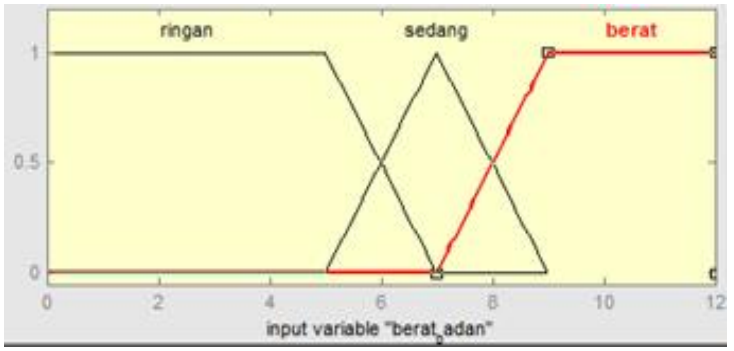

Gambar 7. Himpunan Fuzzy Berat Badan

Untuk memperjelas grafik di atas ada pada keterangan tabel di bawah ini:
Tabel 2. Humpunan Fuzzy Berat Badan

\begin{tabular}{|c|c|c|c|c|}
\hline $\begin{array}{c}\text { Semesta } \\
\text { Pembicaraan }\end{array}$ & Himpunan & $\begin{array}{c}\text { Model } \\
\text { MF }\end{array}$ & Domain & Parameter \\
\hline \multirow{3}{*}{0.12} & Ringan & Trapmf & 0.7 & {$[0057]$} \\
\cline { 2 - 5 } & Sedarg & Trimf & $5-9$ & {$[579]$} \\
\cline { 2 - 5 } & Berat & Trapmf & $7-12$ & {$[79.1212]$} \\
\hline
\end{tabular}

c. Variabel Panjang Badan

Adapun gambar himpunan fuzzy variabel panjang badan adalah:

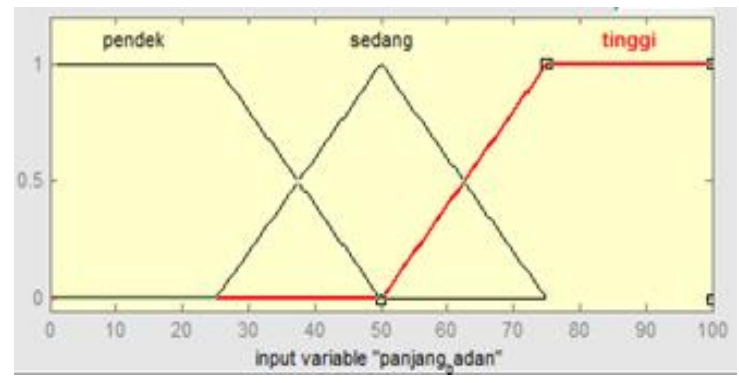

\section{Gambar 8. Himpunan Fuzzy Panjang Badan}

Untuk memperjelas grafik di atas ada pada keterangan tabel di bawah ini:

Tabel 3. Humpunan Fuzzy Panjang Badan

\begin{tabular}{|c|c|c|c|c|}
\hline $\begin{array}{c}\text { Semesta } \\
\text { Pembicaraan }\end{array}$ & Himpunan & $\begin{array}{c}\text { Model } \\
\text { MF }\end{array}$ & Domain & Parameter \\
\hline \multirow{3}{*}{$0-100$} & Pendek & Trapmf & $0-50$ & {$\left[\begin{array}{llllll}0 & 0 & 2 & 5 & 5 & 0\end{array}\right]$} \\
\hline & Sedang & Trmf & $25-75$ & {$\left[\begin{array}{llll}2 & 50 & 75\end{array}\right]$} \\
\hline & Tinggi & Trapmf & $50-100$ & {$[5075 \quad 100100]$} \\
\hline
\end{tabular}

Contoh kasus:

Dari data sebuah kantor dinas kesehatan terdapat kasus seorang balita yang berumur 3 tahun, berat badan $=5 \mathrm{~kg}$ dan panjang badan $=50 \mathrm{~cm}$. Apakah status gizi bayi tersebut? Dalam pengerjaan mamdani terlebih dahulu 
menetukan fuzzyfikasi seperti dalam penyelesaian berikut:

a. Himpunan fuzzy untuk Umur 3, terletak pada kurva sedang $\mu$ sedang [3]

$$
\begin{aligned}
& =(x-a) /(b-a) \\
& =(3-2) /(3-2) \\
& =1 / 1 \\
& =1
\end{aligned}
$$

Himpunan fuzzy untuk Umur3, terletak pada kurva tinggi

$$
\begin{aligned}
\mu \text { tinggi [3] } & =(x-a) /(b-a) \\
& =(3-3) /(4-3) \\
& =0 / 1 \\
& =0
\end{aligned}
$$

b. Himpunan fuzzy untuk Berat Badan 5, terletak pada kurva ringan

$$
\begin{aligned}
\mu \text { ringan [5] } & =(\mathrm{d}-\mathrm{x}) /(\mathrm{d}-\mathrm{c}) \\
& =(7-5) /(7-5) \\
& =1 / 1 \\
& =1
\end{aligned}
$$

Himpunan fuzzy untuk Berat Badan $5 \mathrm{~kg}$, terletak pada kurva sedang

$$
\begin{aligned}
\mu \text { sedang [5] } & =(x-a) /(b-a) \\
& =(5-5) /(7-5) \\
& =0 / 2 \\
& =0
\end{aligned}
$$

c. Himpunan fuzzy untuk Panjang Badan 50 $\mathrm{cm}$, terletak pada kurva sedang

$$
\begin{aligned}
\mu \text { sedang [50] } & =(\mathrm{d}-\mathrm{x}) /(\mathrm{d}-\mathrm{c}) \\
& =(50-50) /(50-25) \\
& =0 / 25 \\
& =0
\end{aligned}
$$

Himpunan fuzzy untuk Panjang Badan 50 $\mathrm{cm}$, terletak pada kurva sedang

$$
\begin{aligned}
\mu \text { sedang }[50] & =(x-a) /(b-a) \\
& =(50-25) /(50-25)
\end{aligned}
$$

$$
\begin{aligned}
& =25 / 25 \\
& =1
\end{aligned}
$$

2. Pengumpulan (Aggregation)

IF (Umur isSedang) AND (Berat Badan isRingan) AND (Panjang Badan is Sedang)

THEN(Keputusan is Gizi Sangat Kurang).

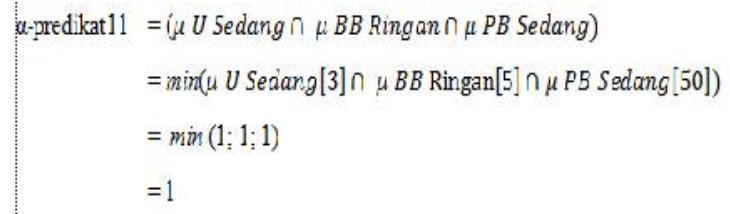

\section{Kombinasi (Combination)}

Pembentukan komposisi aturan dilakukan dengan cari pengambilan nilai max pada $\alpha$ predikat, setiap nilai min pada aturan dikomposisikan dengan fungsi max yaitu :

$$
\begin{aligned}
\mu \text { hasil } \quad & =\max \{\mathrm{R} 11\} \\
& =\max \{1\} \\
& =1
\end{aligned}
$$

4. Defuzzifikasi

Selanjutnya adalah mencari nilai defuzzifikasi dengan metode centroid:

$$
\begin{aligned}
& Z^{*}=\frac{(1 * 20)}{1} \\
& Z^{*}=\frac{20}{1} \\
& Z^{*}=20 \text { (Gizi Sangat Kurang) }
\end{aligned}
$$




\section{HASIL PENGUJIAN}

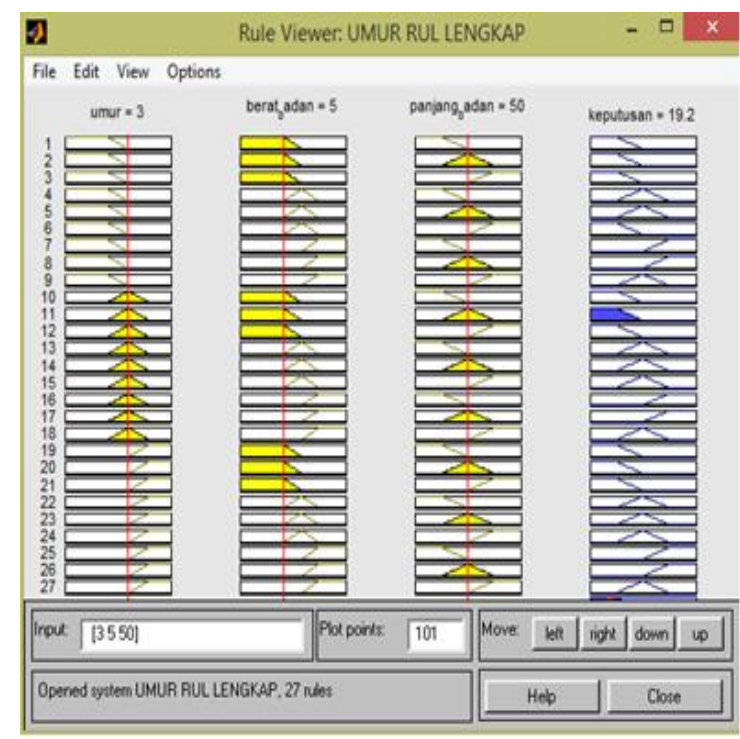

Gambar 9. Hasil Pengujian Menggunakan Matlab

Pada gambar di atas hasil pengujian menggunakan matlab adalah 19,2 sedangkan perhitungan manual adalah 20 yang memiliki selisih sebesar 0,8 namun masih tetap dalam range yang sama dan meiliki keputusan yang sama juga yaitu gizi sangat kurang.

\section{KESIMPULAN}

Dari analisa di atas ,maka dapat disimpulkan yaitu:

1. Metode Mamdani dapat diterapkan dalam melakukan perhitungan untuk mencari nilai stauts gizi pada balita.

2. Dalam menentukan status gizi penulis membutuhkan sedikitnya 3 variabel sebagai input seperti umur, berat badan, panjang badan dan 1 variabel output yaituberupa keputusan. Knowledge atau rule yang dihasilkan dengan sistem aplikasi MATLAB digunakan untuk menentukan status gizi berdasarkan variabel yang ada.
3. Dari hasil pengujian dengan metode Fuzzy Mamdani pada Matlab didaptkan keputusan yang sama dalam menentukan status gizi.

\section{DAFTAR PUSTAKA}

Chai, Yuanyuan, et al.2009." Mamdani Model based Adaptive Neural FuzzyInference System and its Application". World Academy of Science, Engineering and Technology Volume 3.

Eniyati. 2011. "Perancangan Sistem Pendukung Pengambilan Keputusan Untuk Penerimaan Beasiswa Dengan Metode SAW (Simple Additive Weighting)". Jurnal Teknologi Informasi DINAMIK Volume 16 Nomor 2, Juli 2012.

Harison. 2013. “Analisa Sistem Pendukung

Keputusan Penentuan Kosentrasi Jurusan Teknik Mesin UNP Padang”. Jurnal TEKNOIF Volume 1 Nomor 1, April 2013.

Jayanti, Sherly dan Sri Hartati. 2012. "Sistem Pendukung Keputusan Seleksi Anggota Paduan Suara Dewasa Menggunakan Metode Fuzzy Mamdani”. Jurnal IJCCS, Volume 6 Nomor 1, Januari 2012.

Kaur, Arshdeep and Amrit Kaur. 2012. “ Comparison of Mamdani-Type and Sugeno-Type Fuzzy Inference Systems for Air Conditioning System”. IJFLS Volume 2 Nomor , May 2012.I

Kusumadewi, Sri dan Hari Purnomo. 2010. "Aplikasi Logika Fuzzy Untuk Pendukung Keputusan”. Graha Ilmu: Yogyakarta.

Magdalena, Hilyah.2012.” Sistem Pendukung Keputusan Untuk Menentukan Mahasiswa Lulusan Terbaik Di Perguruan Tinggi (Studi Kasus STMIK ATMA Luhur 
Pangkalpinang)". Jurnal Sentika: Pangkal Pinang.

Mardison. 2012. “ Sistem Pendukung Keputusan Dalam Pencairan Kredit Nasabah Bank Dengan Menggunakan Logika Fuzzy Dan Bahasa Pemograman Java”. Jurnal Teknologi Informasi dan Pendidikan Volume 5 Nomor 1, Maret 2012.

Naba, Agus. 2009. "Belajar Cepat Fuzzy Logic MenggunakannMATLAB”. Andi Offset: Yogyakarta.

Nasr, A. Saberi. 2012. "Analysis of Groundwater Quality using Mamdani Fuzzy Inference System (MFIS) in Yazd Province, Iran". International Journal of Computer Applications Volume 59 Nomor 7, Desember 2012.
Nezhad, Qasem Abdollah, et al. 2013. “ An Investigation On Fuzzy Logic Controllers (Takagi-Sugeno \& Mamdani) in Inverse Pendulum System". IJFLS Volume 3 Nomor 3, July 2013.

Suyanto. 2008. "Soft Computing Membangun Mesin Ber-IQ Tinggi". Informatika: Bandung.

Vasant, Elamvazuthi, et al. 2009. "The Application of Mamdani Fuzzy Model for Auto Zoom Function of a Digital Camera. IJCSIS Volume 6 Nomor 3, 2009.

Widiastuti, Nelly Indiani. 2012. "Model Perilaku Berjalan Agen-Agen Menggunakan Fuzzy Logic”. Jurnal Komputer dan Informatika (KOMPUTA) Volume 1 Nomor 1, Maret 2012. 